EMBRYARIDDLE
Aeronautical University

SCHOLARLY COMMONS

\section{International Journal of Aviation,} Aeronautics, and Aerospace

\title{
The Challenges of Processing Kite Aerial Photography Imagery with Modern Photogrammetry Techniques
}

Jeremy W. Aber

Middle Tennessee State University, jeremy.aber@mtsu.edu

Tyler A. Babb

Middle Tennessee State University, tyler.babb@mtsu.edu

Follow this and additional works at: https://commons.erau.edu/ijaaa

Part of the Aeronautical Vehicles Commons

\section{Scholarly Commons Citation}

Aber, J. W., \& Babb, T. A. (2018). The Challenges of Processing Kite Aerial Photography Imagery with Modern Photogrammetry Techniques. International Journal of Aviation, Aeronautics, and Aerospace, 5(2). https://doi.org/10.15394/ijaaa.2018.1210

This Article is brought to you for free and open access by the Journals at Scholarly Commons. It has been accepted for inclusion in International Journal of Aviation, Aeronautics, and Aerospace by an authorized administrator of Scholarly Commons. For more information, please contact commons@erau.edu. 


\section{The Challenges of Processing Kite Aerial Photography Imagery with Modern Photogrammetry Techniques}

\section{Cover Page Footnote}

This project was supported in part by the NASA-Tennessee Space Grant Consortium. Special thanks to Nicholas Dennis and Tim Newell for their assistance in processing the KAP imagery. 
Kite aerial photography (KAP) imagery has been used for over a century in a variety of contexts, and part of what makes this technique of data collection useful is that the images can be analyzed using the same approaches as those used for plane- or satellite-based platforms while providing a much higher ground resolution. This article explores some image processing and analysis techniques with an eye to any special considerations to the KAP method. Many of these considerations are similar to those carried out with imagery collected via planes or unmanned aerial systems (UAS), and UAS platforms can share some of the same issues. One of the biggest differences between these approaches is that a KAP approach is tethered and tends to have a higher amount of variability in angle, rotation, and height at the time of image capture. This can necessitate additional image preparations and may affect the output quality of automated image processing approaches. For this study, multiple software packages were tested to see if they were capable of taking a standard set of KAP images and combining them into a composite image covering a particular site in Murfreesboro, TN. The outputs of these packages were compared for both qualitative and quantitative accuracy to determine which is best suited for processing KAP imagery. For software that used a photogrammetry approach, the $3 \mathrm{D}$ point clouds generated were also compared for quality. As a secondary practical consideration, the cost and ease of use of these software packages were also considered.

\section{Literature Review}

KAP is a method of aerial image collection that involves 'low-tech' tethered platforms including kites, helium blimps, hot air balloons, and heavy-duty weather balloons. KAP is an old technique, predating the plane- and satellite-based approaches commonly employed in remote sensing work. Indeed, aerial photography has existed almost as long as photography itself, with some the first aerial photographs of Paris taken via hot air balloon in the late 1850s by GaspardFélix Tournachon, also known by his pseudonym, Nadar (Frizot, 1998). The earliest known individual to explicitly use a kite for collecting imagery is Arthur Batut, another Frenchman who lifted a camera equipped with an altimeter and fuse for controlling the shutter in the late 1880s (Benton, 2010). From the latter part of the $19^{\text {th }}$ century on, tethered kite and blimp platforms were used in many applications, including military reconnaissance; however, many of these tethered photography applications switched to the use of airplanes after the proliferation of flight in the 1920s and 30s (Hart, 1982).

For much of the $20^{\text {th }}$ century, KAP was essentially a lost art aside from a small number of dedicated individuals (Beauffort \& Busariez, 2010; Hart, 1982). However, the technique was rediscovered and found to have many practical 
applications not available with other image capturing platforms. The primary benefits of KAP imagery are the ability to gather local low cost, high-resolution imagery. The pixel resolution of KAP imagery is anywhere from sub-centimeter to several centimeters per pixel depending on the camera model used and the distance from the Earth's surface. Capturing KAP imagery also tends to be relatively fast and flexible when compared to the process of collecting imagery via plane. With these benefits, KAP fills a niche between ground-based and plane-based observations.

Today, applications for KAP imagery are broad ranging. For example, researchers have used KAP to monitor penguin populations and intertidal zones (Bryson, Johnson-Roberson, Murphy, \& Bongiorno, 2013; Fraser, Carlson, Duley, Holm, \& Patterson, 1999). In both of these cases, the use of a tethered platform is important to gather data due to atmospheric conditions that could pose a challenge for a UAS approach. Vegetation monitoring is another common use with Aber, Sobieski, Distler, and Nowak (1999) discussing the use of the technique to provide sub-pixel data to use with Landsat Thematic Mapper imagery. The collection of near-infrared imagery has also become widely available thanks to modern digital imaging platforms, and Aber, Aber, and Leffler (2001) discuss the use of KAP with near-infrared cameras for the monitoring of vegetation conditions. The identification and study of landforms have also been approached using KAP, including Quaternary landscapes in Poland (Aber \& Galazka, 2000). Also, researchers have used KAP to help map ice and periglacial landforms in Alaska (Boike \& Yoshikawa, 2003).

The mapping of landforms with KAP imagery can also be undertaken in three dimensions through the use of photogrammetry techniques. Marzolff and Poesen (2009) and Smith, Chandler, and Rose (2009) both used this approach to create high-resolution 3D digital elevation models of the Earth's surface. Human and historical subjects have also been studied, such as research which used imagery to identify unmarked graves in a potter's field (Aber, Aber \& Pavri, 2002). Archaeological sites have also been assessed via aerial imaging including KAP techniques (Verhoeven, 2009). Sklaver, Manangan, Bullard, Synberg, and Handzel (2006) used the technique to quickly assess a refugee camp in Eastern Chad, exploring the potential for KAP to be employed in humanitarian emergencies.

The range of software applications for the image processing techniques explored in this study is also broad but split based on the technical methods used to work with imagery. Some of the software packages tested here are based on algorithms that match images to stitch together panoramic image composites. The ability to automatically align and stitch images is a technique commonly used in 
the field of computer vision for the generation of panoramas, as well as being a component of image stabilization for cameras (Szeliski, 2006). Both of these applications are embedded in virtually all consumer-grade camera equipment today and are used to create photo panoramas at home.

The other type of image processing explored here is based on a photogrammetry approach. Photogrammetry can be defined as "any measuring technique allowing the modeling of a 3D space using 2D images" (Egels \& Kasser, 2004 , p. 1). For much of the $20^{\text {th }}$ Century, photogrammetry work was based on aerial imagery captured from planes, and was most often used to generate maps and elevation models of the Earth's surface. Today, many fields benefit from photogrammetric techniques, particularly since inexpensive handheld cameras can be used to collect suitable imagery. Some applications include studying natural phenomena and behaviors such as erosion, river channels, glacial ice, and tornadoes (James \& Robson, 2012; Lane, 2000; Ryan et al., 2015; Wakimoto, Atkins, \& Wurman, 2011). Archaeologists have used photogrammetry to model field sites and reconstruct ancient structures since the $19^{\text {th }}$ century, although the specific techniques and technologies employed have become more sophisticated over time (Al-Ruzouq, 2012; Carbonnell, 1968; Drap et al., 2003; Fussell, 1982).

Engineers use the technique for material testing and structure monitoring in civil engineering situations (Han, Hong, \& Kim, 2012; Maas \& Hampel, 2006). Transportation accidents are studied using photogrammetry as well. In the case of auto accidents, close range ground-based photography is used. For other types of accidents, the National Transportation Safety Board has begun to use UAS platforms to collect imagery for analyses of incidents such as rail and airplane crashes (Karpowicz, 2017; Xinguang, Xianlong, Xiaoyun, Jie, \& Xinyi, 2009).

In photogrammetry, 2D dimensional images are used to generate a 3D point cloud, which is a collection of points, each with unique $\mathrm{X}, \mathrm{Y}$, and $\mathrm{Z}$ attributes, that can be displayed and rotated in a three-dimensional space. In this study, the photogrammetry software use two different approaches to creating these point clouds. The first is the traditional method that PhotoModeler Scanner is based on. In this approach, a user links a set of images with ground control points and ensures that camera lens parameters are set in the software. Based on that information, the software will reconstruct the scene, but additional user input is often required to remove outlier points with high levels of error to improve the point cloud model. PhotoScan and Pix4D both employ a newer technique, known as structure from motion (SfM). Very little manual input is required for an SfM method, as derives its $3 \mathrm{D}$ point cloud output automatically, using image matching techniques to derive camera location and lens factors (Fonstad et al., 2011; Westoby, Brasington, 
Glasser, Hambrey, \& Reynolds, 2012). In a traditional digital photogrammetry approach, ground control points are required to generate a point cloud; in SfM, control points are only necessary to tie an existing point cloud to a known coordinate space. The SfM method is significantly easier to do from a user perspective, as it requires much less input and can use any camera source since the lens information is automatically derived. One drawback to the SfM approach to photogrammetry is that if images are collected in a highly regular pattern, as if often the case with grid-like UAS flights, a vertical doming effect can occur in the point cloud (James \& Robson, 2014). The introduction of more variance in image rotation, angle, and height can help mitigate this effect, something that the KAP approach inherently provides.

\section{Method}

The images used to illustrate these processes were collected on March $16^{\text {th, }}$ 2014 in Murfreesboro, Tennessee. This particular date was chosen because the flying conditions and lighting were ideal with clear skies and steady wind, allowing for many high-quality images to be collected. The location is along the city's greenway, a paved recreational trail system that follows the path of the Stones River. The ground cover at this site is varied, including humanmade structures, managed vegetation such as grass and shrubs, unmanaged trees and vegetation along the Stones River, and the river itself. Additionally, the images processed in this study were adjacent to the path of a severe EF4 tornado incident on April $10^{\text {th }}$, 2009. Fig 1 shows the aftermath of the tornado captured via plane the day after the incident; the site this study focuses on is just below the bottom edge of the photo.

The camera platform employed was assembled and customized from a commercially available kit, an example of which can be seen in Figure 2. Two cameras were used during this image collection session, a Canon ELPH PowerShot 130IS, and a Tetracam ADC Lite digital infrared camera. Both cameras were chosen for their ease of integration with the remote rig and their light weights. The image compositing and point cloud generation were all based on a common set of 29 images collected by the Canon PowerShot, the images from the infrared camera were used to explore the pansharpening technique, but are not included in the image compositing process. Each camera was flown in a separate flight, but within 30 minutes of one another in the early afternoon to ensure similar lighting conditions across both sets of images.

The kite lifting the cameras was a Fled model made by G-Kites. This kite is designed to fly in relatively low windspeeds of five to twelve miles per hour as measured on the ground, while maintaining a high line angle (Conrad, n.d.). 
Although stronger winds are typically preferable for most kites, this particular model is a good match for lifting the camera platform seen in Figure 2. Naturally, larger cameras require larger kites and higher wind speeds, but the Fled is an excellent option for low wind speed conditions and was used in this study.

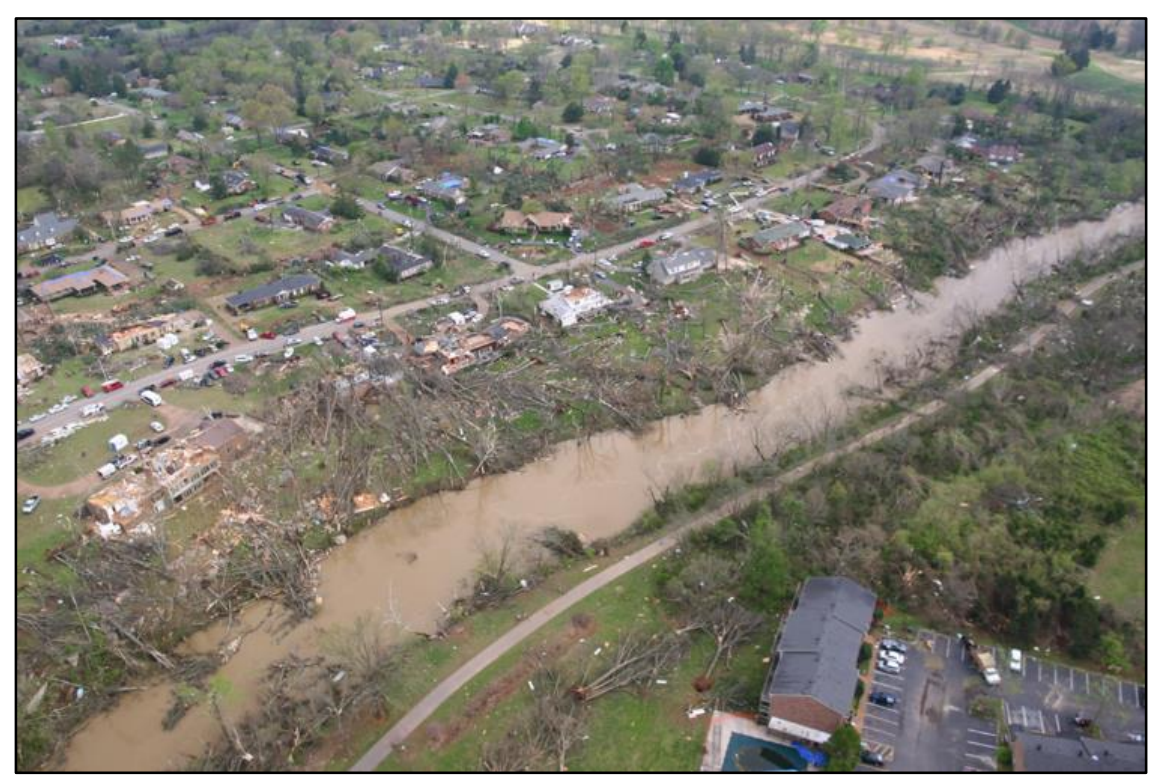

Figure 1. Image of the aftermath of the 2009 EF4 tornado (Hatchett, 2009).

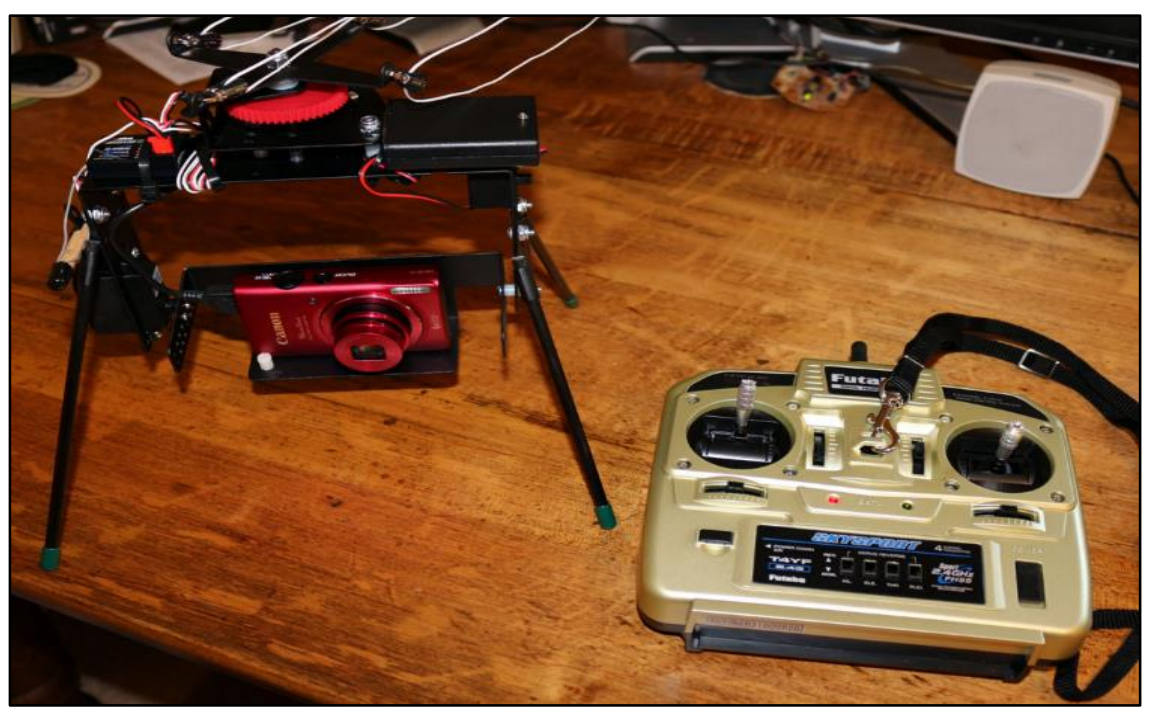

Figure 2. Remotely Controlled Camera Rig Holding the Canon ELPH PowerShot 130IS. 
High powered or exotic hardware was not required for running the software in this study, although a faster computer will naturally cut down on the time required for processing imagery. In this case, the computer used was a standard Windows desktop PC. Georectification of composite image outputs and pansharpening operations were completed in ArcGIS 10.3. The georectification process was made possible by capturing GPS locations for visible landmarks in the field using an Archer XF101 DGPS handheld receiver running ArcPad.

Unlike working with air photos or satellite imagery prepared by commercial or governmental agencies, KAP imagery requires some preprocessing before it can be used for georectifying, pansharpening, and photogrammetry operations. This is similar to working with UAS imagery, in that it is often collected locally and viewed in a raw format rather than purchased or downloaded in a processed form. Images must be sorted and linked to a proper geographic coordinate space so that they can be used in the further geospatial analysis.

Sorting was done to determine which images were of a suitable quality, as sudden gusts of wind during a flight had a negative impact on image capture. Images may be blurry or angled too high to be properly georectified. Images of the horizon are useful for providing context to the site and can be stitched into panoramas using software such as Microsoft Image Composite Editor (Microsoft ICE), but they are not suitable for georectification, as flattening them to fit the Earth's surface would cause a high level of distortion in the image. Figure 3 shows an oblique image that can be used to understand the site's context but cannot be effectively georectified to fit the surface.

Next, the images were georectified so that they could be displayed as a single layer covering the study site. Georectification takes aerial imagery and by tying it to ground control points, aligns the images to a geographic coordinate space. In this study, it is also used as a measure of the quality of the image composites. The process of georectification generates a root mean square (RMS) error of the transformation from arbitrary to known coordinate space. This RMS error can be used to assess the quality of the composite images, as an image with low RMS error will more accurately align with the locations of the ground control points. If one image composite has a higher RMS error, this means that it was less accurate in its compositing process, thus allowing for a comparison of the different software packages' abilities. 


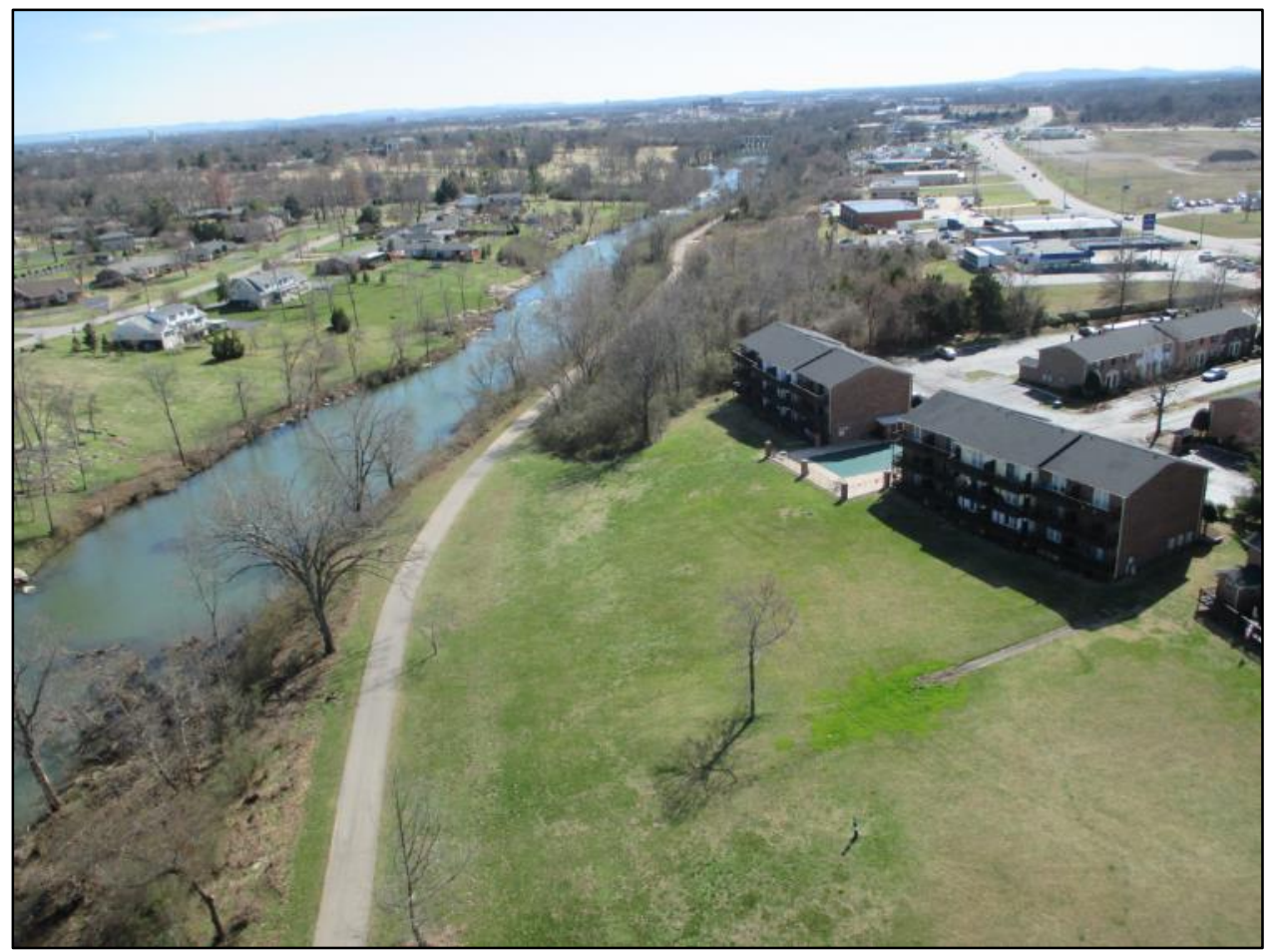

Figure 3. Oblique shot showing the region of the site that was in the tornado path.

After georectifying the images, it is possible that some areas of the study area simply were not captured during the flight. Also, while the camera may be set to a fixed exposure during a flight, changes in the angle of the camera and sunlight conditions can lead to issues when combining the images. When displayed as individual layers in ArcGIS, each image is displayed based on its unique color histogram, and adjacent images may appear to have dramatically different exposures despite being taken just seconds apart. Some color correction options are available within ArcGIS, but they are not necessarily capable of blending transitions perfectly, and their use requires yet another processing step. Figure 4 shows off a mosaic of post-georectification imagery from the Greenway site that highlights issues of gaps in coverage and transitions between images.

The processing and georectifying of each image are time-consuming, as a flight session will capture dozens, even hundreds of images. However, this study employed automated software approaches to reduce the amount of manual labor involved by compositing image sets into a single image. Instead of georectifying dozens of individual images, as in Figure 4, larger composite images were georectified a single time to achieve greater coverage with less effort. Figure 5 shows a comparison of individually georectified images to a composited image. The composite image still has some amount of spatial error, as can be seen in the 
results section. While the spatial resolution of the individual images may be on the order of a few centimeters per cell, the spatial accuracy cannot be assumed to match, given the potential for error in the image compositing and georectifying processes, as well as the error inherent in DGPS measurements of ground controls. Additionally, the output of an image-stitching panorama program will not be as accurate as a photogrammetry-based approach, which corrects geometry to account for camera angles.

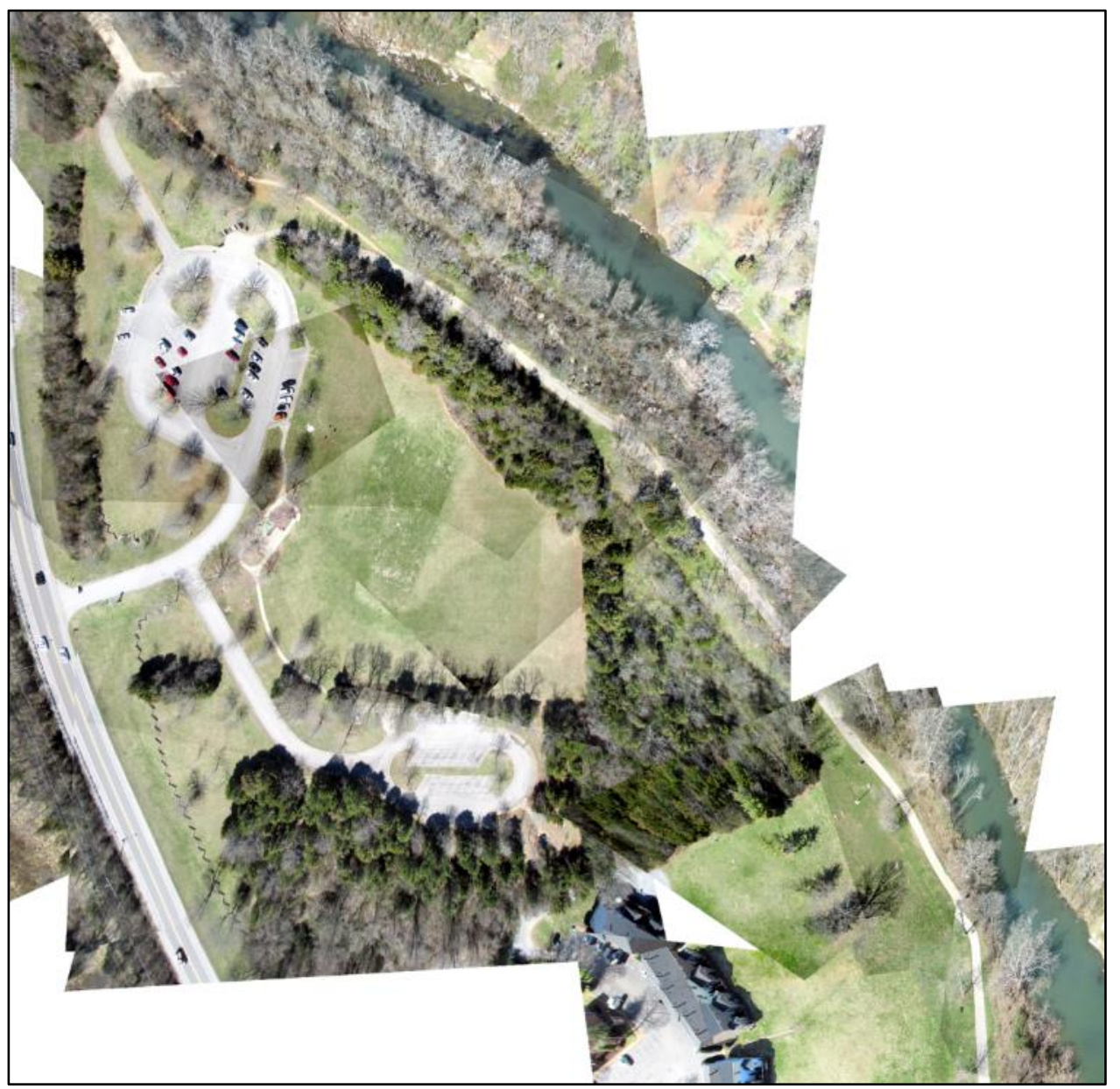

Figure 4. A collection of images individually georectified and displayed in ArcGIS.

For compositing this set of imagery, several programs were tested, some of which are freely available. Software using an image compositing panoramic approach include Adobe Photoshop's Photomerge tool (commercial), Kolor's Autopano Giga (commercial), and Microsoft ICE (free), while those that employ photogrammetry techniques (all commercial) include PhotoModeler Scanner, 
PhotoScan, and Pix4D Mapper. PhotoModeler uses the older traditional photogrammetry approach as previously discussed, and has been around for many years now with developer Eos Systems releasing the first version in the early 1990s (Eos Systems, 2018). PhotoScan from Agisoft and Pix4D are both much more recent in their technology, employing the modern structure-from-motion technique and released in 2010 and 2011 respectively (Agisoft, 2018; Pix4D, n.d.).

These packages were chosen with a practical applied perspective in mind, as this software is commonly used and would be found in many commercial and academic environments. In the case of the photogrammetry-based packages, an additional consideration is that these packages are 'complete' in the sense that they capable of handling every step of the photogrammetry process from start to finish. There are many open source and commercial packages that do one or more of the steps in a typical photogrammetry workflow, but the software chosen here simplifies the process by handling everything with a common user interface (Falkingham, 2016).

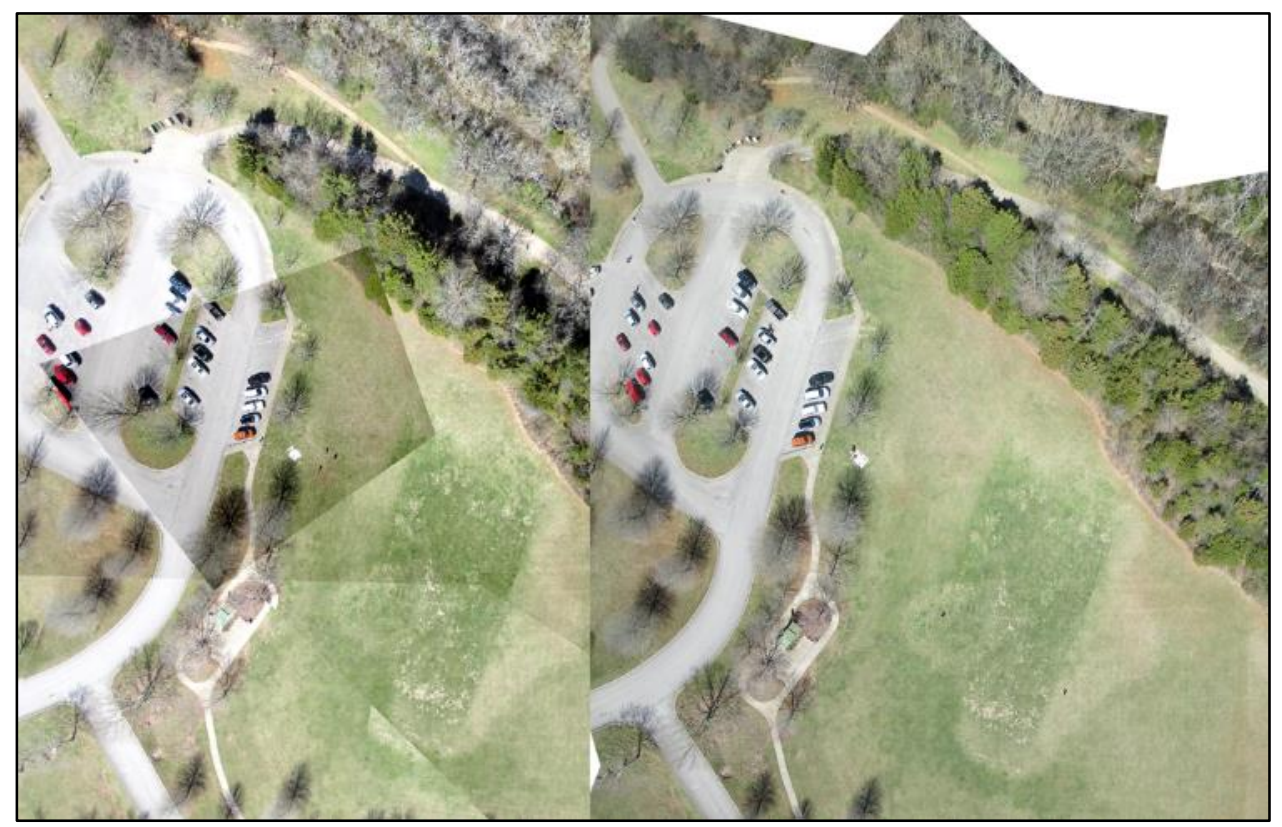

Figure 5. Comparison of individual georectified images to a georectified composite section.

The biggest hurdle to the compositing process is the irregularity of the KAP source images. A traditional approach to generating a photographic panorama involves much less variance of camera rotation than a typical KAP operation. A common set of 29 images covering the study site was used for all the programs 
tested. Most portions of the images overlap with at least one other image in the set, ensuring that the software packages have enough information to align the images, but some areas on the edges of the site naturally have less coverage. To compare the results of the different software packages, the outputs were georectified using a set of ten ground control points consistent in their order of application and the resulting RMS error was recorded in meters. A second set of ten different ground control points was also used to assess the spatial accuracy of the images. In the case of composite images generated through a photogrammetry approach, the point clouds were given an arbitrary coordinate system so that a georectifying transformation could be applied to assess quality. Also, the 3D point clouds generated by the photogrammetry-based software packages were compared for quality relative to one another using the open source software package CloudCompare. The point clouds were aligned using control points so that they would exist in the same coordinate space relative to one another, then the distance between the clouds was measured to give a quantitative assessment of the differences.

The image compositing process takes the neatly rectilinear data from the camera and rotates and distorts it to create a good alignment with the other images. A composited image output will therefore likely have an irregular, polygonal shape, which can lead to some minor issues. When georectifying and overlapping composite imagery, ArcGIS will fill the empty edge spaces with black cells that can obscure other images displayed below. The user can specify that these cells are made transparent, but this often leads to noisy borders around the edges of the images, which is less than ideal. The visual noise can be distracting, especially when it overlaps another image. If aerial imagery with an irregular border has black cells along edges, one method of improving on this situation is to manually remove the black cells. The image needs to be saved in a format that supports transparency, such as the portable network graphics format (png). These images can then be edited in Photoshop or another suitable image manipulation program to remove the black borders and replace them with transparent cells. This dramatically improves image display quality of edges, see Figure 6. When georectifying these transparent images in ArcGIS, it is best to apply the 'Update Georeferencing' option to the png files rather than the Rectify option. A rectification operation will create a new image, and even if a format that supports transparency is chosen as the output file type, ArcGIS will replace the transparent cells with black cells, reintroducing the problem. 


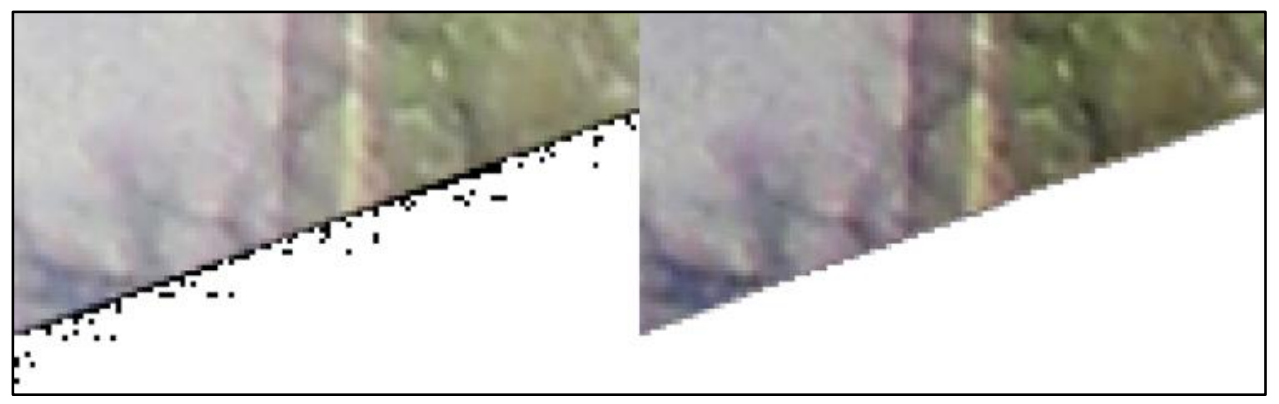

Figure 6. Comparison of edge quality when black NoData cells are made transparent in ArcGIS on the left versus manually making the NoData cells transparent in Photoshop on the right.

The KAP imagery at this site includes near-infrared data captured using a Tetracam ADC Lite that was pan-sharpened to enhance image quality for interpretation. Pansharpening is the process of blending a color image with higher resolution black and white image to enhance image interpretation. The ADC Lite collects information in the green, red, and NIR portions of the electromagnetic spectrum. Tetracam describes these bands as roughly equal to Landsat bands TM2, TM3, and TM4 (Tetracam, 2017). The Canon PowerShot ELPH 130IS that captures visible light takes images with a resolution of $4608 \times 3456$ pixels, while the Tetracam's image resolution is $2048 \times 1536$. Neither of these cameras is meant to replace the other. Instead, they complement one another: the PowerShot with a higher resolution in the visible light spectrum and the Tetracam providing infrared data unavailable to most cameras. Pansharpening is commonly employed with satellite imagery where all image information is collected simultaneously and aligned. In a KAP or UAS application, it is not possible to collect imagery in this manner, so using multiple flights is a necessity.

Since the two cameras could not be flown simultaneously, differences between the images exist regarding angle of the sun and the camera. Flying the two cameras at the same site immediately after one another minimized changes in the sun angle, but the camera angle remained an issue, as there was no way to ensure that the flights would be identical. In a pansharpening operation, the registration of the two images is central to the quality of the output, so images chosen should deviate as little as possible regarding the camera angle. To minimize misregistration created by the georectification process, the first image was georectified to known control points, then that image was used as the basis for georectifying the second, rather than using the control points for both separately. Color information was removed from the true color image via Photoshop. Once the images were prepared and accurately georectified, the pansharpening function of ArcGIS was employed, 
although any GIS or Remote Sensing package would be capable. Figure 7 shows the output of the steps in this process.

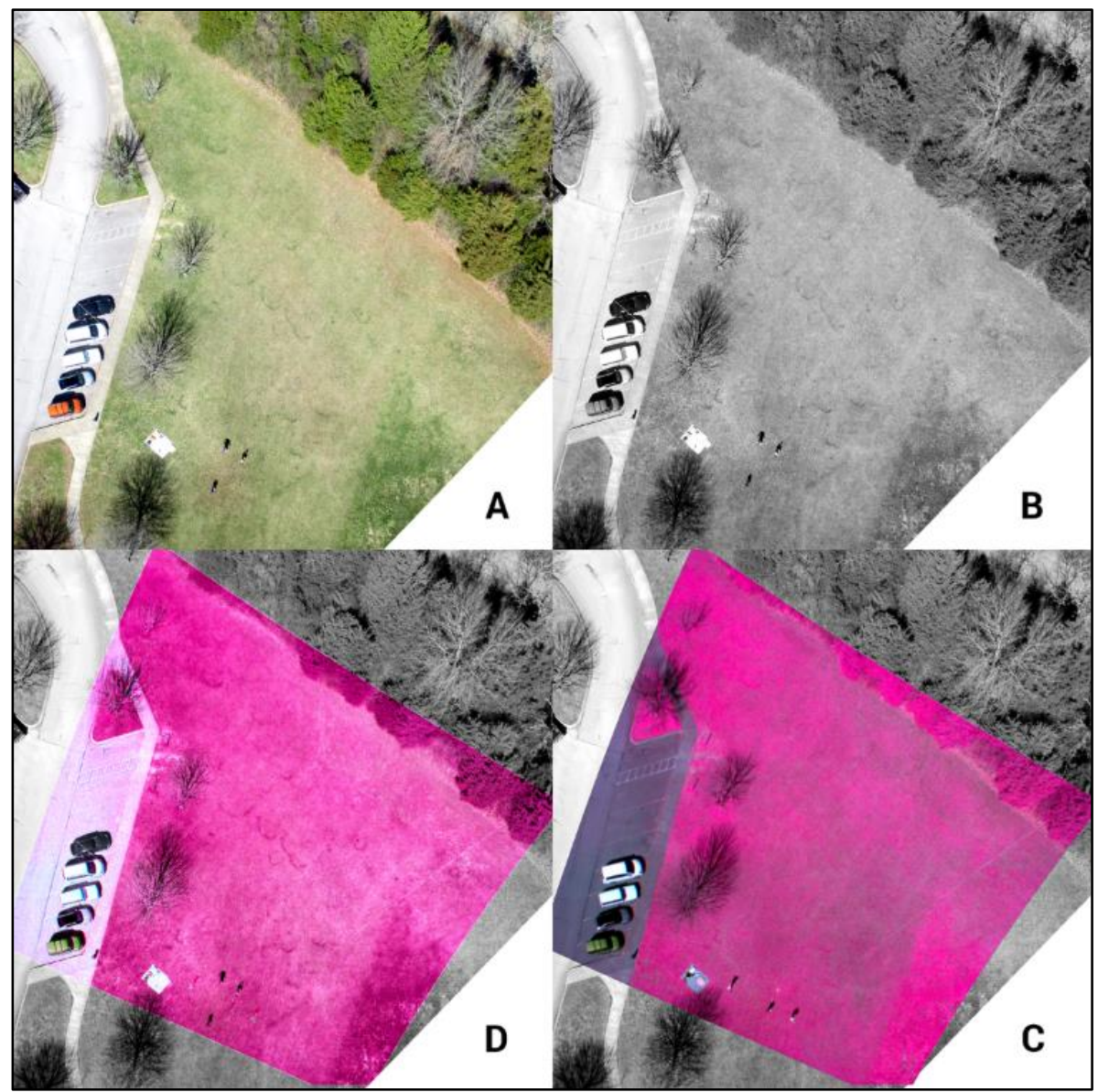

Figure 7. Four images showing the progression of the pansharpening process for KAP imagery using ArcGIS. Clockwise from the top left: (A) the original true-color high resolution photo; (B) the same image stripped of color information; (C) the original lower resolution false-color NIR image georectified but otherwise unmodified; and (D) a pansharpened view employing the IHS approach. Note that while many features are easier to distinguish in the pansharpened output, some have shifted between the two flights. The presence of an additional car in the parking lot and the location of researchers in the field are the most obvious in this case.

\section{Results}

Four of the software packages tested were capable of compositing the images in a satisfactory manner: PhotoModeler Scanner, PhotoScan Professional, Pix4D Mapper, and Microsoft ICE. The three photogrammetry packages provided 
the highest quality output. It is not surprising that the photogrammetry approach was more successful in generating accurate composited images, given that the process involves correcting for distortions in geometry. Their outputs were all suitable for use, but there were some noticeable differences in quality. The experience of using these four software packages was similarly mixed in quality.

The non-photogrammetry software produced lower quality results, with different stitching approaches to image compositing working with varying degrees of quality. Some of the software packages tested generated unsatisfactory output, and would not be recommended as options for processing KAP imagery. Both Adobe Photoshop's Photomerge tool and Kolor's Autopano Giga were capable of blending images with a good level of visual transition quality, but the relative placement of the images was of unacceptably low quality. In both cases, the images were often nowhere near the proper location they ought to have been, to the point that it would not even be possible to carry out a georectifying operation for quality assessment. That Autopano Giga had trouble with this was somewhat surprising, given that the developer Kolor is owned by GoPro, the camera company whose products are often used to capture consumer UAS imagery (O'Kane, 2015). These programs are certainly capable of generating high-quality panoramic image composites, but it seems the levels of variance in image rotation and angle in this data set were too large for them to handle. It is possible that some preprocessing of the images, such as rotating them all to match a common orientation, might have helped to generate better outputs, but that would defeat the purpose of using an automated approach to reduce image processing time.

Microsoft ICE was the sole panoramic image compositing software able to successfully stitch the 29-image set into a coherent output with an acceptable level of visual quality. ICE's output can be seen in Figure 8. ICE allows the user control over the methods used in the compositing process. In this case, a planar projection was chosen for the image processing, as it best represented the movement of the camera and generated the best overall image quality regarding alignment and visual clarity. Overall, the image quality was good, but it still had issues aligning some of the images, particularly at the edges where there is less overlap, and the camera angle was higher relative to the ground. Earlier tests with fewer images in the data set had less trouble with alignment in some places, indicating that ICE is sensitive to inputs, so adding or removing a single image could potentially improve the overall output quality. 


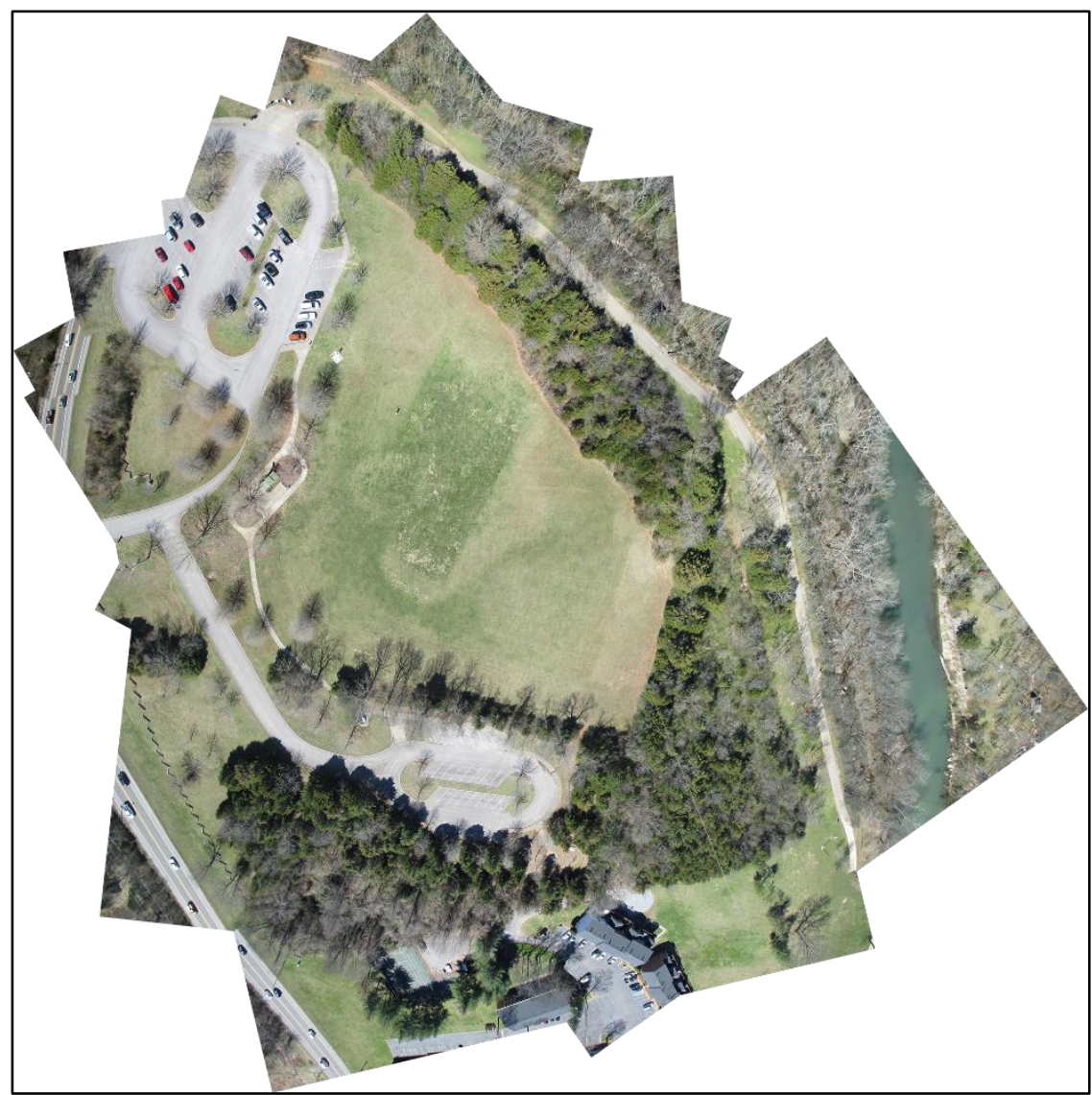

Figure 8. The output of the Microsoft ICE software combining all 29 images.

The photogrammetry software had a better rate of success, with all three software packages capable of processing and outputting the imagery. Based on the point clouds that were generated, the software creates an orthophoto, an image that has been geometrically corrected and flattened to remove camera angle and lens distortions. Figure 9 shows the orthophoto output from PhotoModeler Scanner. PhotoModeler uses a traditional photogrammetric approach to generating its output. Figure 10 shows the output from PhotoScan, and Figure 11 shows the output of Pix4D. Both PhotoScan and Pix4D employ a structure from motion approach to generating their point clouds. One of the biggest practical differences between the three photogrammetry packages is how they responded to edge areas with less image overlap. Each package generated different extents to their respective point clouds. PhotoScan covered the largest extent, but like PhotoModeler still had gaps in the coverage. Pix4D did not cover quite as large a ground extent, but within the area, it did cover there were no gaps. 
The comparison of these four composite image outputs is broken down into two categories, a qualitative visual approach, and a quantitative spatial accuracy approach based on georectifying with ground control points. Considering visual quality, none of the methods produce error-free images; Figure 12 shows a comparison. Microsoft ICE generated the best overall image quality since much of the surface shows unmodified image data, but the areas where images connect sometimes introduced tearing, overlapping, and duplication of features that did not occur nearly as much in the photogrammetry-based outputs. The biggest challenge for the photogrammetry packages appears to be the bare deciduous trees in the image, likely because these represent complex 3D structures that are difficult to reproduce in a point cloud. As Figure 12 shows, all the images have imperfections, with distortion, tears, and misplaced surfaces affecting all of the software packages to varying degrees. Of the three photogrammetry approaches, PhotoScan has the best overall image quality with the least amount of visual distortion. However, PhotoScan also had issues with the trees, as evidenced by the wavy look of the curb beneath the branches.

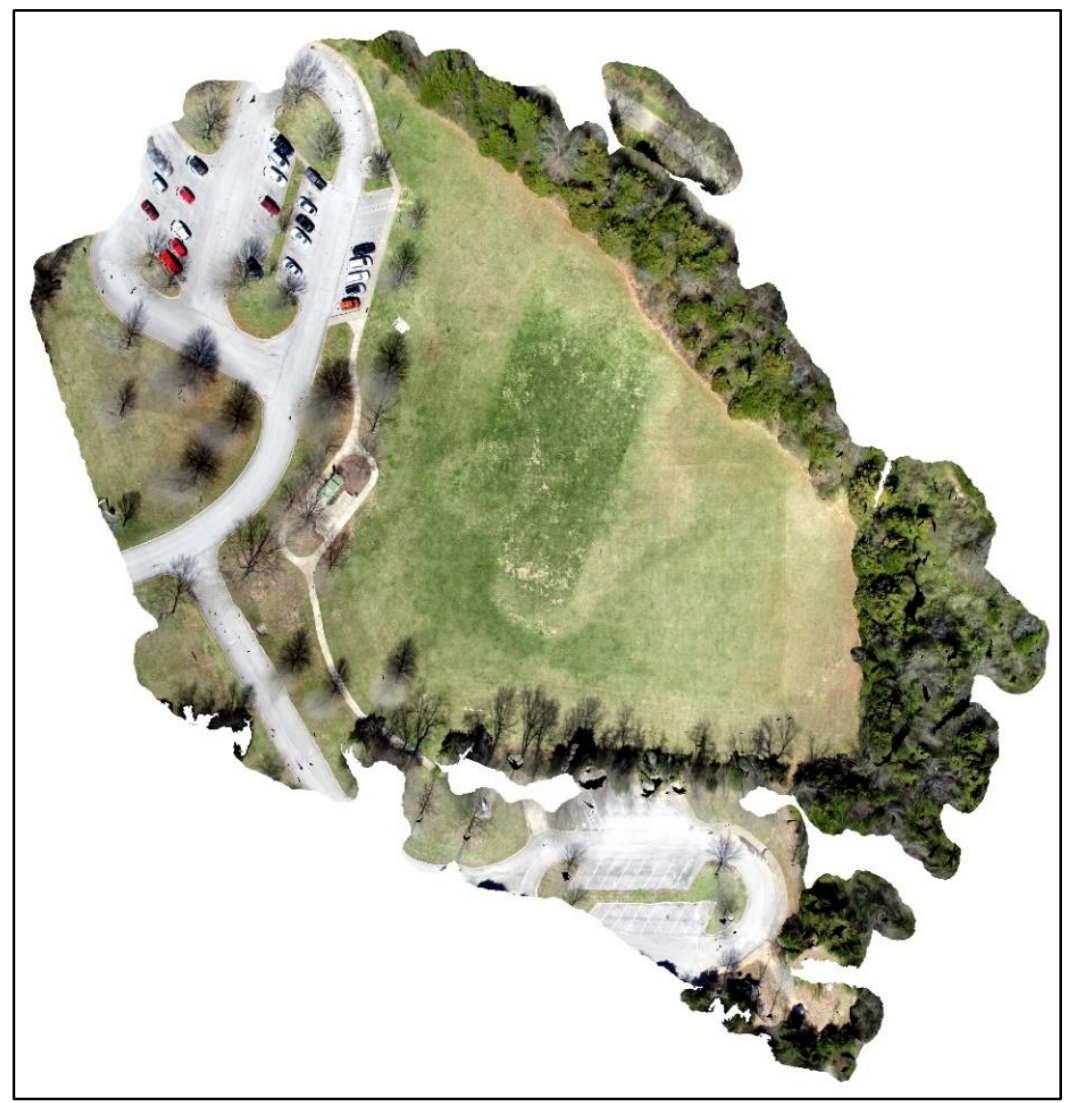

Figure 9. The output of the PhotoModeler Scanner software combining all 29 images. 


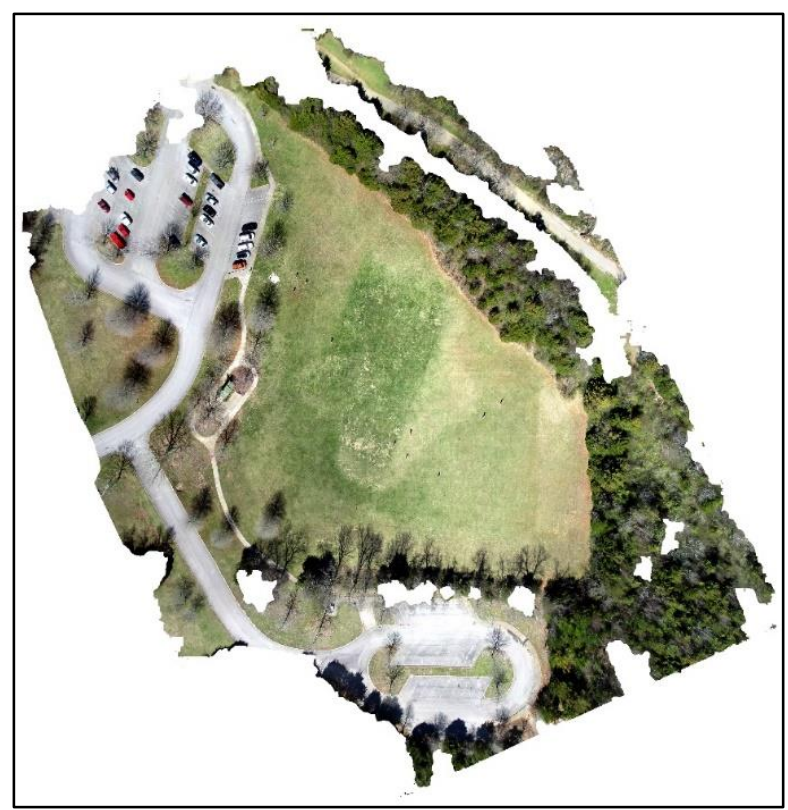

Figure 10. The output of the PhotoScan software combining all 29 images.

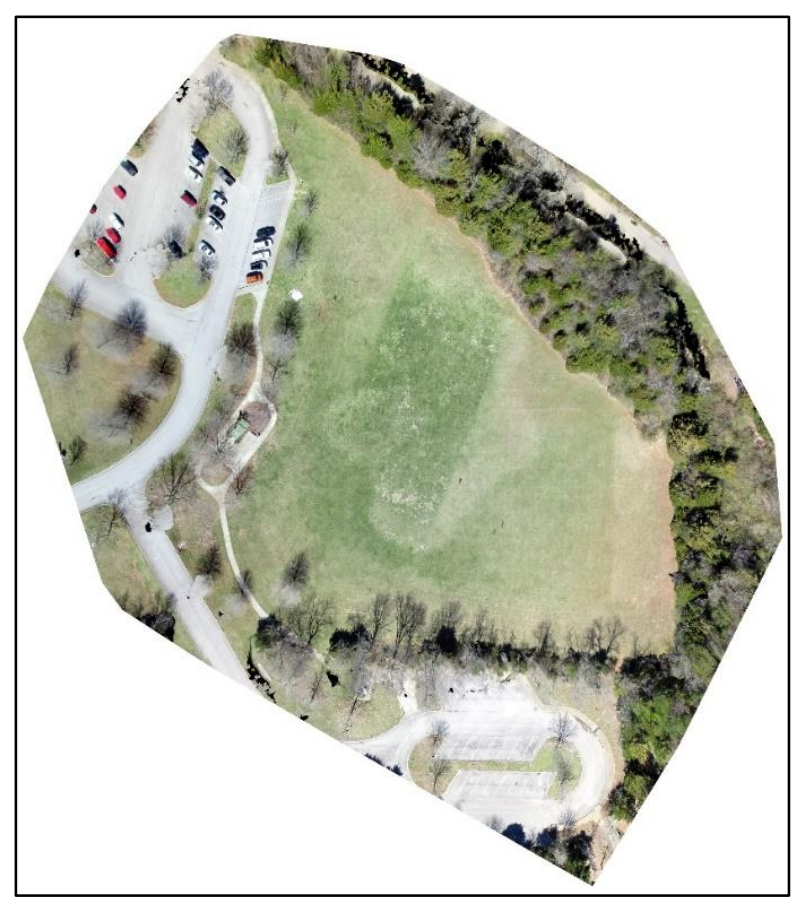

Figure 11. The output of the Pix4D software combining all 29 images. 


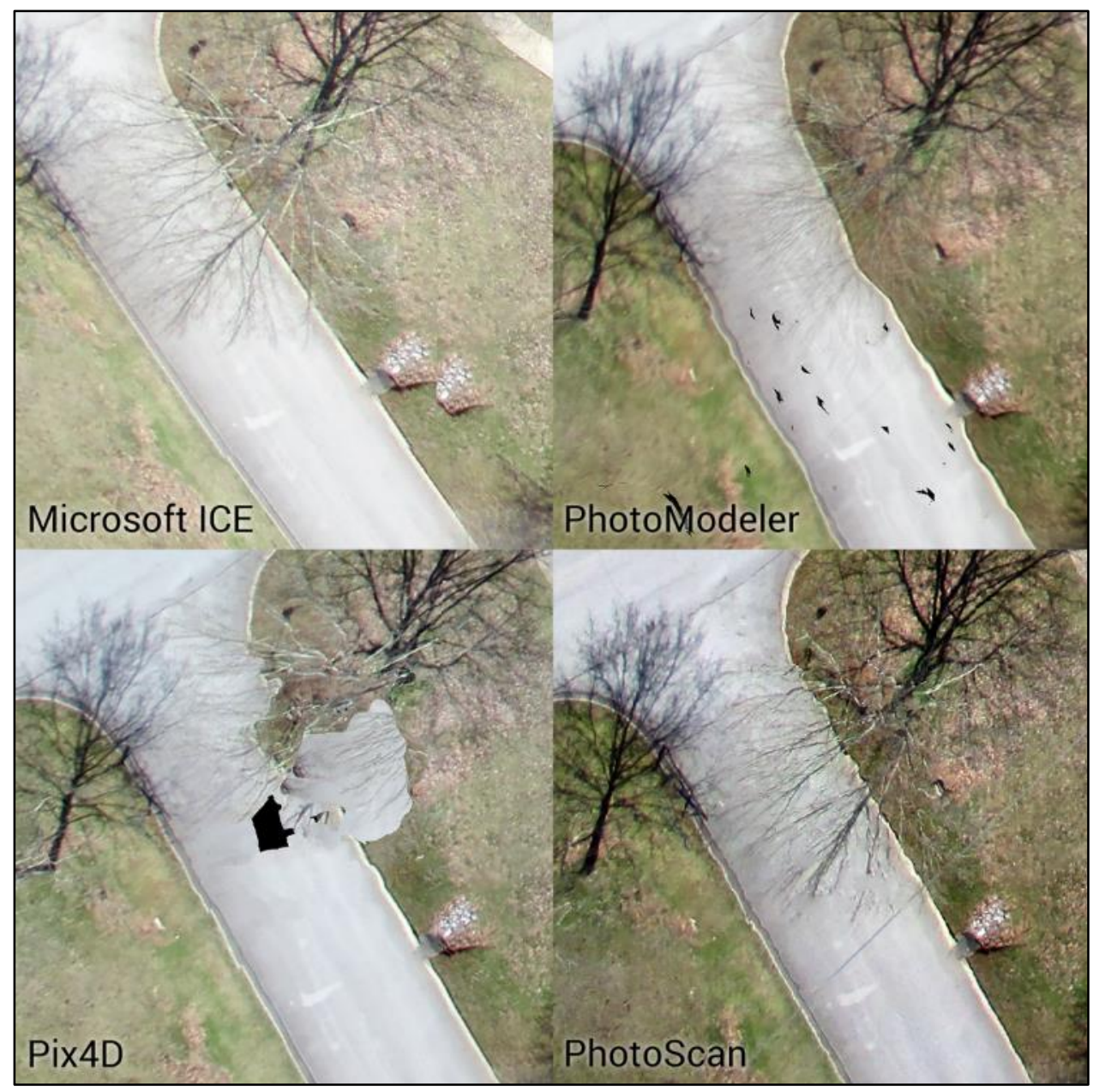

Figure 12. A visual comparison of the four image compositing approaches.

Table 1 shows the overall root mean square error of each image georectification operation. All the photogrammetric approaches had similarly low levels of error both during the georectifying transformation and after being georectified. Unsurprisingly, the Microsoft ICE output had much higher error, as it did not correct for camera angles the way the photogrammetric software packages did. 
Table 1

RMS Error in meters for the three photogrammetric software packages

\section{Microsoft ICE PhotoModeler PhotoScan Pix4D}

$\begin{array}{lllll}\text { Georectifying } & 0.669 & 0.144 & 0.132 & 0.142 \\ \text { Error } & 0.669\end{array}$

Post-

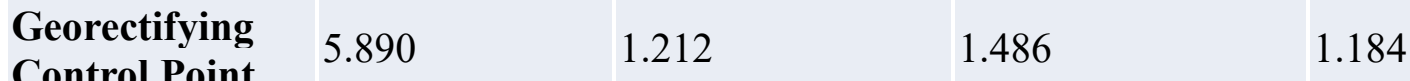

Error

Analysis of the point clouds revealed that all three software packages were able to generate coverage for the area, especially in the middle of the site where the largest amount of image overlap existed. The edges showed the biggest differences regarding the spatial extent and fullness of the point clouds generated. Figure 13 shows the point clouds as visualized in CloudCompare. Airborne LiDAR data exists for this area, but the density of points is so much lower than the clouds generated from the KAP imagery that no meaningful comparison could be made. Since no reference surface exists for this site, the point clouds were compared relative to one another. The PhotoScan output was used as the reference cloud for comparison as it had the fullest point coverage across the largest spatial extent.

Since none of the images had embedded GPS data, manual ground control points had to be added using the WGS84 coordinate system. This was explicitly done to align the clouds to a common geographic coordinate space so that they could be compared to one another. The process was straightforward in PhotoModeler and PhotoScan, but when control points were added to the point cloud in Pix4D, the cloud lost cohesion, see Figure 14 and compare to the cloud in Figure 13. Pix4D also consistently generated its initial arbitrary point cloud with the $\mathrm{X}$ and $\mathrm{Z}$ coordinates swapped, and manual constraints were required to fix the orientation. Because of the inability to add control points in Pix4D, the point cloud had to be manually aligned in CloudCompare to fit the same WGS84 coordinate space as the other two clouds.

Figures 15 and 16 show the results of the comparisons between the point clouds made using CloudCompare's cloud-to-cloud distance tool. Most of the points are well under a meter apart, with the largest differences occurring along the edges and in the tree canopies. This was expected, as there was less image data on the edges to generate the clouds, and the bare trees are complex structures. 
Individual branches may or may not be distinguishable enough at the scale of this imagery to build an accurate model. Both PhotoModeler and PhotoScan had a flattening effect on these bare trees, making them appear much shorter than they are. The points generated to represent bare trees are of questionable quality in all the point clouds, but Pix4D did the best job of modeling their true heights. Figure 17 shows a comparison of the bare trees.

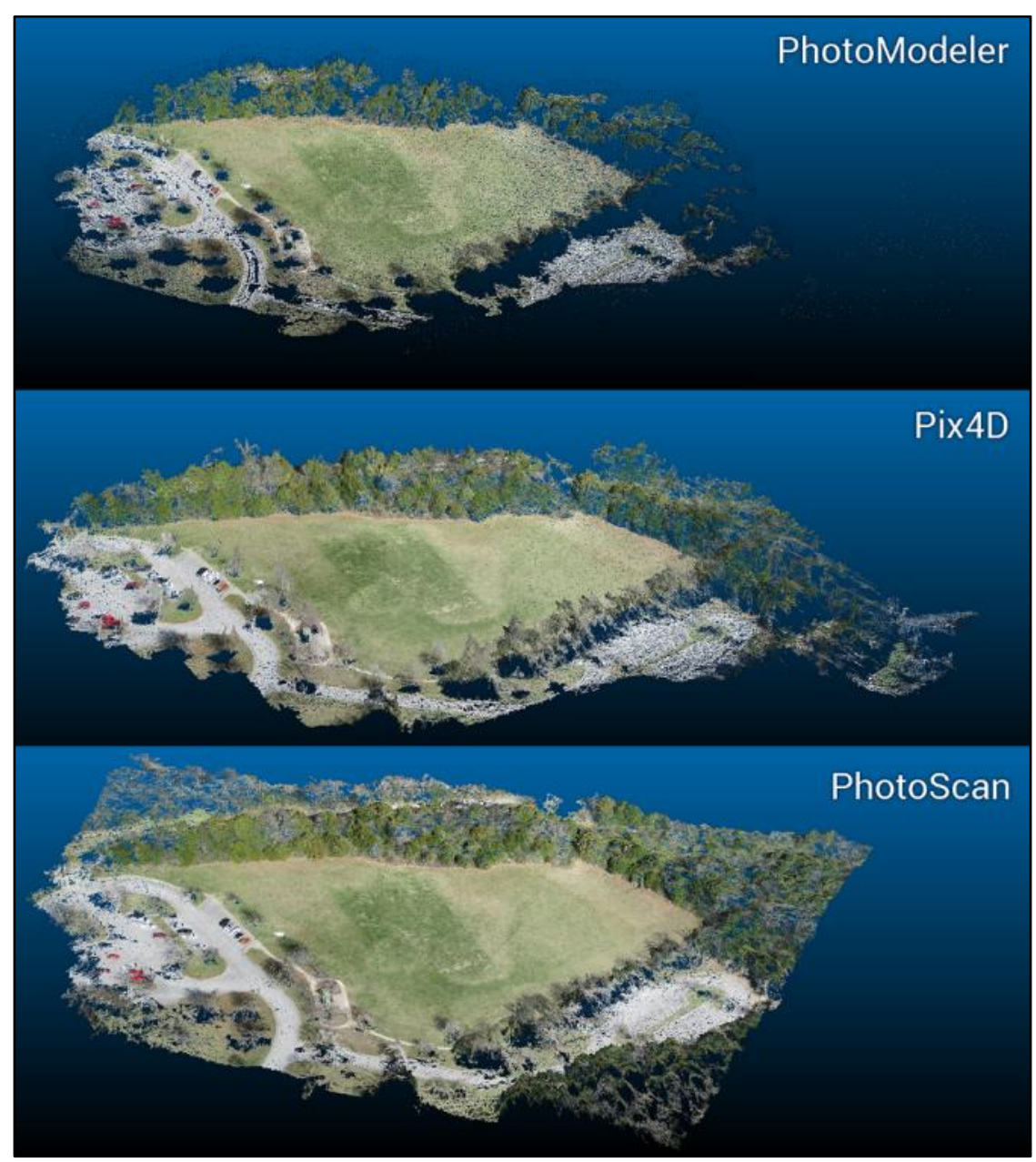

Figure 13. The point clouds as visualized in CloudCompare. 
International Journal of Aviation, Aeronautics, and Aerospace, Vol. 5 [2018], Iss. 2, Art. 2

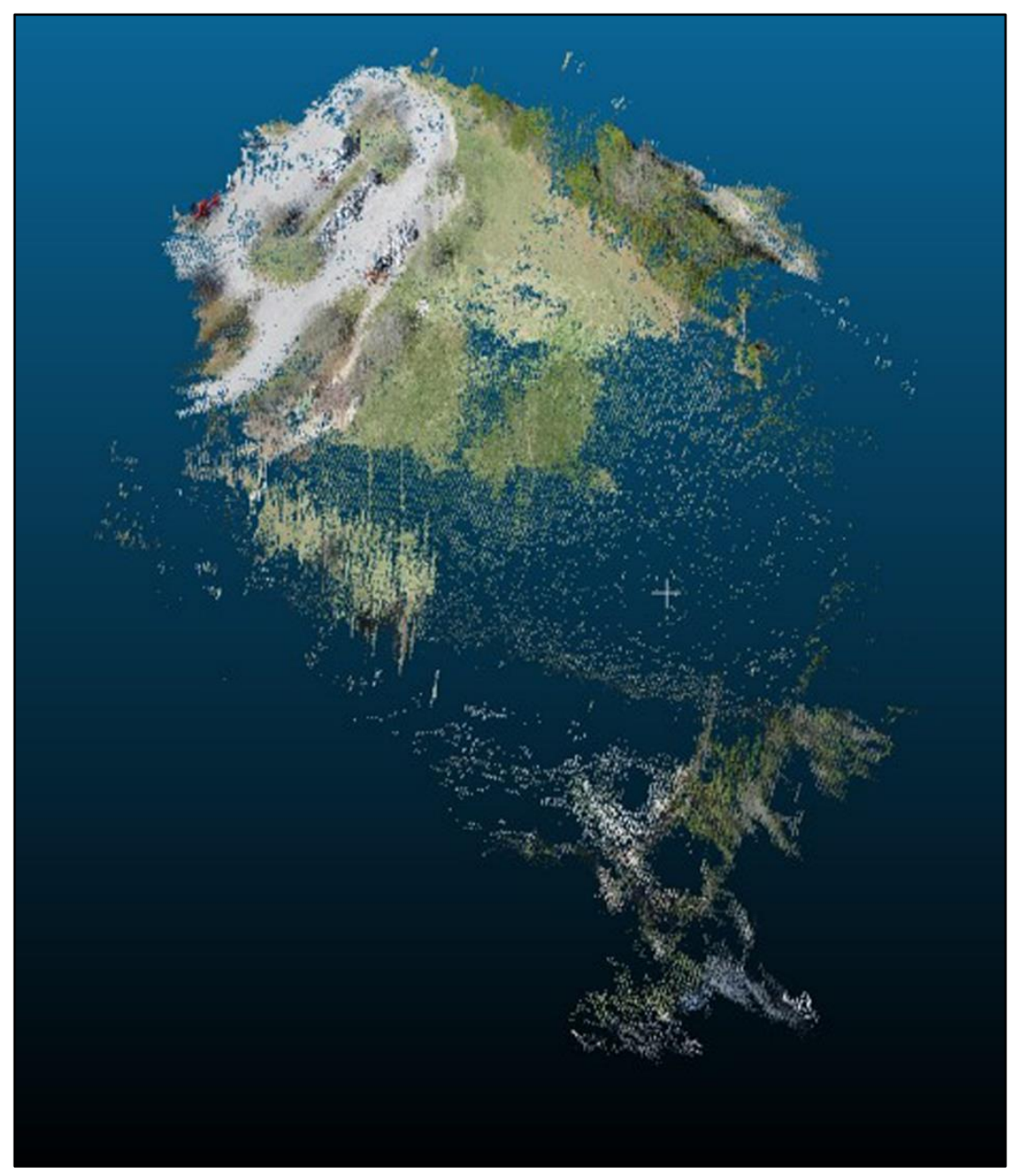

Figure 14. The unusual Pix4D point cloud after attempting to add ground control points. 


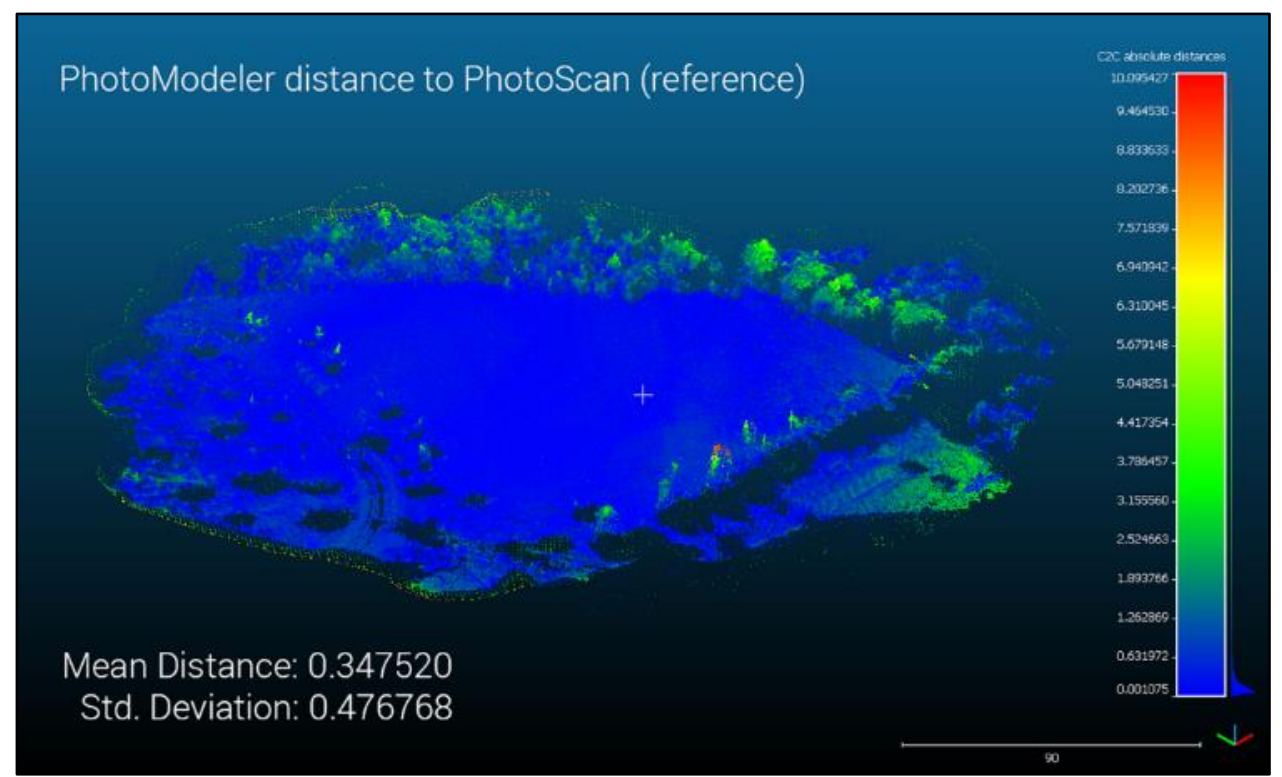

Figure 15. Cloud-to-cloud distance between the PhotoModeler and PhotoScan point clouds.

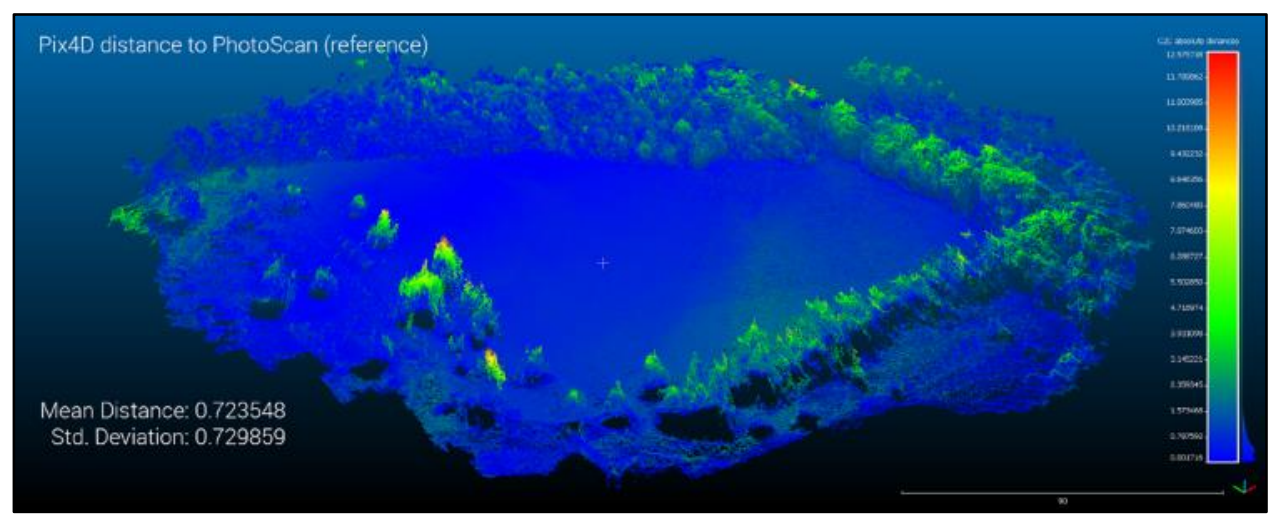

Figure 16. Cloud-to-cloud distance between the Pix4D and PhotoScan point clouds. 


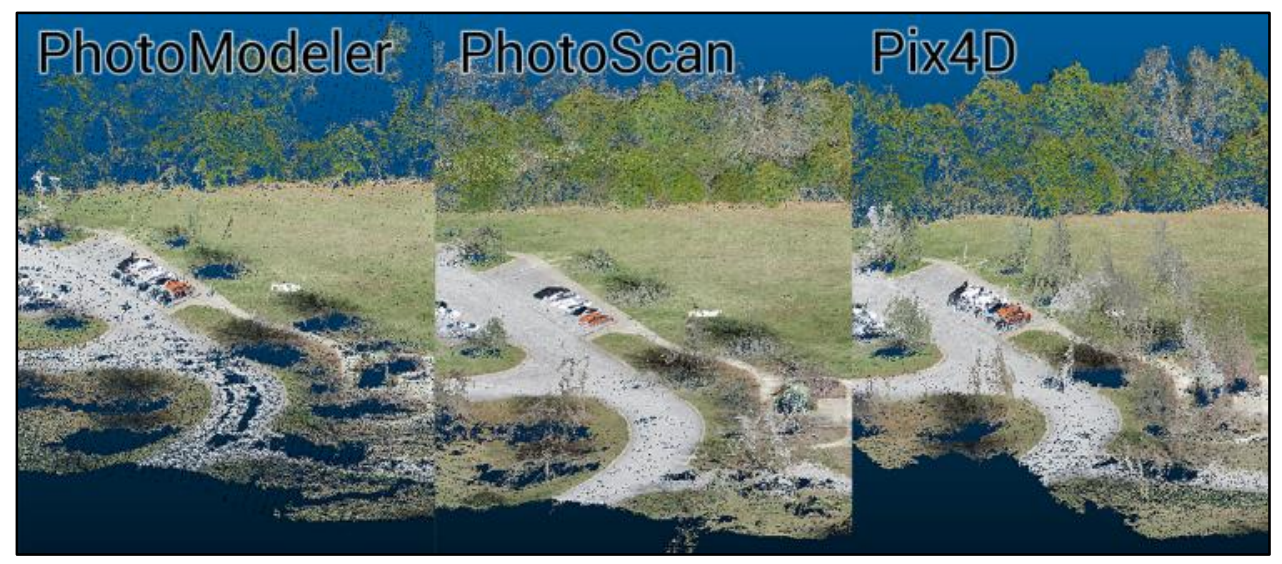

Figure 17. A look at the bare trees in the point clouds, with Pix4D doing the best job of representing the true heights of the bare trees.

\section{Discussion}

These software programs allow users to survey areas quickly and accurately. The ability to do so proves useful to a myriad of industries, ranging from geography to accident investigations. All three photogrammetry packages compared could generate detailed point clouds. It would be difficult to claim that any of the three photogrammetry packages was best since the overall quality of their outputs were similar and each had their complications. Pix4D did the best job of representing the $\mathrm{Z}$ factor of the trees in the scene, but it required more manual adjustment to avoid glitched output. In particular, the issue with adding ground control points to the Pix4D software that rendered the cloud incoherent is a problem. It is unknown if this problem is limited to this particular set of images or a more widely experienced issue. With its traditional photogrammetry approach, PhotoModeler required the most user input to run by far, but this also allows for a high level of control during the process. PhotoScan generated the largest spatial coverage and had the best overall visual quality when composited orthophotos were compared, but the point cloud did not do as well in generating accurate tree heights.

The cost of the software is also a practical factor to be considered. Microsoft ICE is free to download and use, but the output of its image composite had a much higher error component than the commercial photogrammetry packages. It also does not generate a $3 \mathrm{D}$ point cloud for the imagery, which allows for further analyses in addition to orthophoto generation. Each of the commercial photogrammetry packages has multiple licensing options including yearly maintenance or one-time costs for perpetual licenses. Also, PhotoModeler and Pix4D offer different versions of their software with different tools available. The cost of the commercial packages that were compared in this study is summarized 
in Table 2, as described by the developers' online stores as of the time of this writing. Pix4D is by far the most expensive option of the three, although it does offer a non-commercial option that is not available for the other two packages. However, the non-commercial license of Pix4D is more expensive than a commercial license for either PhotoModeler or PhotoScan. Sliding volume discounts are available from the PhotoScan and Pix4D, but the PhotoModeler website does not list any volume discount.

Table 2

Table comparing the cost of different licensure options for the three photogrammetry packages.

\begin{tabular}{|l|l|l|l|l|l|l|}
\hline & $\begin{array}{l}\text { Yearly } \\
\text { Subscription }\end{array}$ & $\begin{array}{l}\text { Monthly } \\
\text { Subscription }\end{array}$ & $\begin{array}{l}\text { Single } \\
\text { Seat }\end{array}$ & $\begin{array}{l}\text { Edu } \\
\text { Single } \\
\text { Seat }\end{array}$ & $\begin{array}{l}\text { Edu } \\
\text { Multi- } \\
\text { Seat }\end{array}$ & $\begin{array}{l}\text { Non- } \\
\text { Commercial } \\
\text { Seat }\end{array}$ \\
\hline $\begin{array}{l}\text { PhotoModeler } \\
\text { Scanner }\end{array}$ & $\$ 1555$ & $\$ 149$ montly & $\$ 2995$ & $\$ 599$ & $\begin{array}{l}\$ 2995 \\
\text { for } 30 \\
\text { seats }\end{array}$ & N/A \\
\hline $\begin{array}{l}\text { PhotoScan } \\
\text { Professional }\end{array}$ & N/A & N/A & $\$ 3,499$ & $\$ 549$ & $\begin{array}{l}\$ 3910 \\
\text { for } 20 \\
\text { seats }\end{array}$ & N/A \\
\hline $\begin{array}{l}\text { Pix4D } \\
\text { Mapper }\end{array}$ & $\$ 3500$ & $\$ 350$ monthly & $\$ 8700$ & $\$ 1990$ & $\begin{array}{l}\$ 6700 \\
\text { for 25 } \\
\text { seats }\end{array}$ & \$4990 \\
\hline
\end{tabular}

For educational purposes, Pix4D remains the most expensive package of the three. PhotoScan is an attractive option for education if only a few seats are required. For bulk licenses to fill a lab, PhotoModeler is by far the cheapest option per seat and may be preferable since the traditional hands-on approach to photogrammetry may be used for instruction purposes. The PhotoScan website does not list bulk educational purchases, but they are available from resellers.

\section{Limitations}

Both the method of KAP image collection and the analysis carried out in this study have some limitations. Because the images collected in this setup do not have embedded GPS data, the initial point clouds existed in arbitrary coordinate systems. This can be remedied by using a camera that embeds GPS data in the images, or by manually adding control points to the dataset as done in this case. 
Given the problems that Pix4D had with manual control point entry, using a GPS enabled camera is recommended.

The analyses in this study are based primarily on a single camera, the Canon ELPH PowerShot 130IS. While the photogrammetry packages were able to detect the camera lens and appropriately correct for lens distortion, it is possible that the use of a higher quality camera during image capture could improve the process. Additionally, only one location was explored in this study. The site was chosen in part because of the variety of structures present, but other sites might have shown different outcomes. In particular, a site without bare trees would likely lead to an increase in the overall quality of the point cloud and orthophoto outputs.

\section{Conclusion}

Regardless of the challenges to the software packages that were tested, all are suitable for processing KAP imagery. Microsoft ICE offers a free image compositing package, but the overall quality was too low to recommend over the photogrammetry approaches. It is possible that an image set with more regularity such as that captured by a programmed UAS flight might lead to better performance in ICE, but the tethered KAP approach is not capable of this level of flight planning. However, the KAP approach offers some benefit to photogrammetry approaches, as the variety of images can reduce error in structure from motion calculations.

In small-format aerial imagery collection situations where a UAS platform is not available or feasible, the KAP approach remains a practical option capable of generating high-quality, centimeter-scale imagery. This imagery is suitable for use with automated software packages that generate image composites and 3D point clouds. While three of the software packages tested are recommended, the ease of use, low cost (particularly for educational users), and quality of visual output gives AgiSoft's PhotoScan Professional a slight edge in this study. For those who need more manual control over the photogrammetry process, PhotoModeler Scanner is recommended. The high cost of licenses and issues with ground control points create practical and operational challenges for Pix4D.

\section{Suggested Additional Research}

Testing the software packages at multiple sites to see if different levels of quality are found would be beneficial for knowing if some of the issues that arose in this study are site-specific or not. It would also be worthwhile to compare UAS and KAP imagery captured at a time and location to see how composites and point clouds generated from a more regularly collected image set compared regarding 
visual and metric accuracy. On that same note, testing multiple camera setups could help answer the question of whether a higher quality lens would have any impact on the software outputs. Adding a camera with embedded GPS capabilities would also potentially affect the photogrammetry process, and would also allow for the testing of Icaros' OneButton photogrammetry software, which requires GPS data to run. 


\section{References}

Aber, J. S., Aber, S. W., \& Leffler, B. (2001). Challenge of infrared kite aerial photography. Transactions of the Kansas Academy of Science, 104(1-2), $18-27$.

Aber, J. S., Aber, S.W., \& Pavri, F. (2002). Unmanned small-format aerial photography from kites for acquiring large-scale, high-resolution, multiview-angle imagery. Pecora 15/Land Satellite Information IV/ISPRS Commission I/FIEOS 2002 Conference Proceedings. Nov 10-15; Denver, CO, US.

Aber, J. S., \& Gałązka, D. (2000). Potential of kite aerial photography for Quaternary investigations in Poland. Geological Quarterly, 44(1), 33-38.

Aber, J. S., Sobieski, R. J., Distler, D. A., \& Nowak, M.C. (1999). Kite aerial photography for environmental site investigations in Kansas. Transactions of the Kansas Academy of Science, 102(1-2), 57-67.

Agisoft. (2018). Agisoft PhotoScan change log - photoscan_changelog.pdf. Retrieved from: http://www.agisoft.com/pdf/photoscan_changelog.pdf

Al-Ruzouq, R. (2012). Photogrammetry for archaeological documentation and cultural heritage conservation. In D. C. da Silva (Ed.), Special Applications of Photogrammetry. 97-110. InTech. Under CC BY 3.0 license. http://doi.org/10.5772/1946

Beauffort, G., \& Busariez, M. (2010 Jun 25). Kite aerial photography - KAPWA Newsletter. Retrieved from: http://kap.ced.berkeley.edu/background/kapwa1.html

Benton, C.C. (2010). Kite aerial photography - The first kite photographs. Retrieved from: http://kap.ced.berkeley.edu/background/history1.html

Boike, J., \& Yoshikawa, K. (2003). Mapping of periglacial geomorphology using kite/balloon aerial photography. Permafrost and Periglacial Processes, 14(1), 81-85. http://doi.org/10.1002/ppp.437 
Bryson, M., Johnson-Roberson, M., Murphy, R.J., \& Bongiorno, D. (2013). Kite aerial photography for low-cost, ultra-high spatial resolution multi-spectral mapping of intertidal landscapes. PLOS One, 8(9). http://doi.org/10.1371/journal.pone.0073550

Carbonnell, M. (1968). The history and the present situation of the application of photogrammetry to architecture. Paris, France: I.C.O.M.O.S.

Conrad, K. (n.d.). KAP Kites, Flying Line, \& Accessories. Retrieved from: http://www.brooxes.com/newsite/BBKK/kitesales.html

Drap, P., Sgrenzaroli, M., Canciani, M., Cannata, G., \& Seinturier, J. (2003). Laser scanning and close range photogrammetryL Towards a single measuring tool dedicated to architecture and archaeology. CIPA XIXth International Symposium, 2003, Turkey. 1-6.

Egels, Y. \& Kasser, M. (2004). Digital Photogrammetry. Taylor \& Francis: New York, NY.

Eos Systems. (2018). About the developers of PhotoModeler - Eos Systems Inc. Retrieved from: http://www.photomodeler.com/connect/about_us.html

Falkingham, P. (2016). Trying all the free photogrammetry! - Dr. Peter L. Falkingham. Retrieved from: https://pfalkingham.wordpress.com/2016/09/14/trying-all-the-freephotogrammetry/

Fonstad, M. A., Dietrich, J. T., Courville, B. C., Jensen, J. L., \& Carbonneau, P. E. (2011). Topographic structure from motion: A new development in photogrammetric measurement. Earth Surface Processes and Landforms, 38(4), 421-430. http://doi.org/10.1002/esp.3366

Fraser, W.R., Carlson, J.C., Duley, P.A., Holm, E.J., \& Patterson, D.L. (1999). Using kite-based aerial photography for conducting Adélie penguin censuses in Antarctica. Waterbirds: The International Journal of Waterbird Biology, 22(3), 435-440. http://doi.org/10.2307/1522120

Frizot, M. (1998). Another kind of photography. In: Frizot, M. The New history of photography. Köln, Germany: Könemann Verlagsgesellschaft mbH. 
Fussell, A. (1982). Terrestrial photogrammetry in archaeology. World Archaeology, 14(2), 157-172. http://doi.org/10.1080/00438243.1982.9979857

Han, J., Hong, K., Kim, S. (2012). Application of a photogrammetric system for monitoring civil engineering structures. In D. C. da Silva (Ed.), Special Applications of Photogrammetry. 73-96. InTech. Under CC BY 3.0 license. http://doi.org/10.5772/1946

Hart, C. (1982). Kites: An historical survey. New York, NY: Frederick A. Praeger.

Hatchett, W. (Photographer). (2009 April 10). Tornado damage that occurred on April 102009 in the City of Murfreesboro TN when it was struck by an EF-4 tornado [photograph]. Retrieved from: https://commons.wikimedia.org/wiki/File:Murfreesboro_tornado_damage. jpg

James, M. R., \& Robson, S. (2012). Straightforward reconstruction of 3D surfaces and topography with a camera: Accuracy and geoscience application. Journal of Geophysical Research, 117(F03). http://doi.org/10.1029/2011JF002289

James, M.R., \& Robson, S. (2014). Mitigating systematic error in topographic models derived from UAV and ground-based image networks. Earth Surface Processes and Landforms, 39(10), 1413-1420. http://doi.org/10.1002/esp.3609

Karpowicz, J. (2017 Nov 7). How are drones being used for NTSB investigations? Commerical UAVNews. Retrieved from: https://www.expouav.com/news/latest/drones-used-ntsb-investigations/

Lane, S. N. (2000). The measurement of river channel morphology using digital photogrammetry. Photogrammetric Record, 16(96), 937-961. http://doi.org/10.1111/0031-868X.00159

Maas, H. \& Hampel, U. (2006). Photogrammetric Techniques in Civil Engineering Material Testing and Structure Monitoring. Photogrammetric Engineering \& Remote Sensing, 72(1), 39-45. https://doi.org/10.14358/pers.72.1.39 
Marzolff, I., \& Poesen, J. (2009). The potential of 3D gully monitoring with GIS using high-resolution aerial photography and a digital photogrammetry system. Geomorphology, 111, 48-60. http://doi.org/10.1016/j.geomorph.2008.05.047

O'Kane, S. (2015). GoPro just bought a virtual reality company. The Verge. Retrieved from: https://www.theverge.com/2015/4/28/8509595/goprovirtual-reality-kolor-acquisition-vr-video

Pix4D. (n.d.). About us - Pix4D. Retrieved from: https://pix4d.com/about-us/

Ryan, J. C., Hubbard, A. L., Box, J. E., Todd, J., Christoffersen, P., Carr, J. R., Holt, T. O., \& Snooke, N. (2015). UAV photogrammetry and structure from motion to assess calving dynamics at Stone Glacier, a large outlet draining the Greenland ice sheet. The Cryosphere, 9, 1-11. http://doi.org/10.5194/tc-9-1-2015

Smith, M.J., Chandler, J.H., \& Rose, J. (2009). High spatial resolution data acquisition for the geosciences: kite aerial photography. Earth Surface Processes and Landforms, 34, 155-161. http://doi.org/10.1002/esp.1702

Sklaver, B.A., Manangan, A., Bullard, S., Svanberg, A., \& Handzel, T. (2006). Rapid imagery through kite aerial photography in a complex humanitarian emergency. International Journal of Remote Sensing, 27(21), 4709-4714. http://doi.org/10.1080/01431160600784309

Szeliski, R. (2006). Image Alignment and Stitching: A Tutorial. Technical Report MSR-TR-2004-92. Redmond, WA: Microsoft Research,

Tetracam. (2017). Tetracam -ADC Lite. Retrieved from: http://www.tetracam.com/Products-ADC_Lite.htm

Verhoeven, G.J.J. (2009). Providing an archaeological bird's-eye view - an overall picture of ground-based means to execute low-altitude aerial photography (LAAP) in archaeology. Archaeological Prospection, 16, 233-249. http://doi.org/10.1002/arp.354

Wakimoto, R. M., Atkins, N. T., \& Wurman, J. (2011). The LaGrange Tornado during VORTEX2. Part I: Photogrammetric Analysis of the Tornado Combined with Single-Doppler Radar Data. Monthly Weather Review, 139(7), 2233-2258. http://doi.org/10.1175/2010MWR3568.1 
Westoby, M. J., Brasington, J., Glasser, N. F., Hambrey, M. J., \& Reynolds, J. M. (2012). 'Structure-from-Motion' photogrammetry: a low-cost, effective tool for geoscience applications. Geomorphology, 179(15), 300-314. http://doi.org/10.1016/j.geomorph.2012.08.021

Xinguang, D., Xianlong, J., Xiaoyun, Z., Jie, S., \& Xinyi, H. (2009). Geometry features measurement of traffic accident for reconstruction based on closerange photogrammetry. Advances in Software Engineering, 40(7), 497505. http://doi.org/10.1016/j.advengsoft.2008.09.002 